\title{
Agreement analysis of three mandibular third molar retention classifications
}

\author{
Robert Stick Rivera-Herrera, ${ }^{1}$ Vicente Esparza-Villalpando, ${ }^{2}$ Josué Roberto Bermeo-Escalona, ${ }^{3}$ \\ Ricardo Martínez-Rider ${ }^{1}$ and Amaury Pozos-Guillén ${ }^{1 *}$ \\ 'Universidad Autónoma de San Luis Potosí, Faculty of Stomatology, San Luis Potosí; '2Universidad Autónoma de San Luis Potosí, Engineering and \\ Science of Materials, San Luis Potosí; ${ }^{3}$ Universidad De La Salle Bajío, Faculty of Dentistry, Guanajuato. Mexico
}

\begin{abstract}
Introduction: Pell \& Gregory and Winter classifications are basic in third molar categorization; Sánchez-Torres classification is used in Mexico, but it has not been previously evaluated. Objective: To assess the degree of agreement in the radiographic evaluation of impacted mandibular third molar with the use of three classifications: Pell \& Gregory, Winter and Sánchez-Torres. Method: Observational, descriptive, inter-observer degree of agreement study that included 10 oral and maxillofacial surgeons and 10 training residents, who recorded the radiographic categorization of third mandibular molars (left and right) according to Pell \& Gregory, Sánchez-Torres and Winter classifications. Inter-observer degree of agreement was assessed with Fleiss' kappa. Results: Pell \& Gregory classification had the lowest degree of agreement (kappa $=0.05$ and 0.185 ), followed by Sánchez-Torres classification (kappa = 0.125 and 0.326); the best value was obtained by the Winter classification, with kappa $=0.28$ and 0.636 for oral and maxillofacial surgeons and training residents, respectively. Conclusion: The Winter classification showed an acceptable (moderate) degree of agreement to classify mandibular third molars by training residents.
\end{abstract}

KEY WORDS: Third molar. Exeresis of retained teeth. Pell \& Gregory classification. Winter classification. Sánchez-Torres classification.

\section{Análisis de concordancia de tres clasificaciones de terceros molares mandibulares retenidos}

\section{Resumen}

Introducción: Las clasificaciones de Pell y Gregory y de Winter son básicas en la categorización de terceros molares; la clasificación de Sánchez Torres es usada en México, pero no había sido evaluada previamente. Objetivo: Evaluar el grado de acuerdo en la valoración radiográfica de terceros molares mandibulares impactados, con el empleo de tres clasificaciones: Pell y Gregory, Winter y Sánchez Torres. Método: Estudio observacional, descriptivo, de concordancia interobservador, que incluyó a 10 cirujanos orales y maxilofaciales y 10 residentes en formación, quienes registraron la categorización radiográfica de terceros molares mandibulares (izquierdos y derechos) de acuerdo con las clasificaciones de Pell y Gregory, Sánchez Torres y Winter. Se evaluó el grado de acuerdo entre observadores mediante la prueba de kappa de Fleiss. Resultados: La clasificación de Pell y Gregory obtuvo el menor grado de acuerdo (kappa = 0.05 y 0.185), seguida de la clasificación de Sánchez Torres (kappa = 0.125 y 0.326); el mejor valor lo obtuvo la clasificación de Winter, con kappa = 0.28 y 0.636 para cirujanos orales y maxilofaciales y residentes en formación, respectivamente. Conclusión: La clasificación de Winter mostró un grado de acuerdo aceptable (moderado) para categorizar terceros molares mandibulares en los residentes en formación.

PALABRAS CLAVE: Tercer molar. Exéresis dental. Clasificación de Pell y Gregory. Clasificación de Winter. Clasificación de Sánchez-Torres.

Correspondence:

*Amaury Pozos-Guillén

E-mail: apozos@uasip.mx
Gac Med Mex. 2020;156:21-25

Contents available at PubMed

www.gacetamedicademexico.com

0016-3813/@ 2019 Academia Nacional de Medicina de México, A.C.. Published by Permanyer. This is an open access article under the CC BY-NC-ND license (http://creativecommons.org/licenses/by-nc-nd/4.0/). 


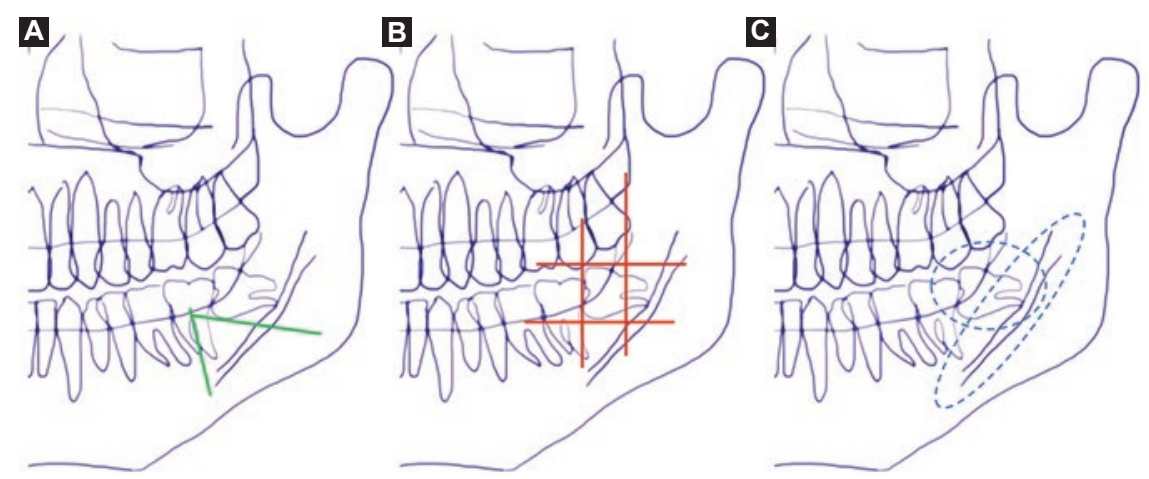

Figure 1. Schematic representation of the most common mandibular third molar classifications. A: Winter classification, based on the position of the third molar in relation to the longitudinal axis of the second molar. B: Pell \& Gregory's classification, based on depth in relation to the occlusal plane of the second lower molar and the mesiodistal diameter of the impacted tooth, according to the distance between the second inferior molar and the anterior part of the mandibular ramus. C: Sánchez-Torres classification, based on three fundamental factors: depth and direction of the third molar, and number, direction and shape of the roots, as well as on two complementary factors: relationship with the inferior dental canal and relationship with the second molar.

\section{Introduction}

Exeresis of retained dental pieces is one of the most recurrent practices in oral and maxillofacial surgery, ${ }^{1}$ especially of mandibular third molars, which are of the dental pieces with the highest rate of impaction. ${ }^{2}$ The indications for dental extraction are varied and are related to the position, shape and pathologies associated with each dental piece. ${ }^{3}$ Third molar anatomical features include multi-cusp, conical or square crowns, among others. In addition, root fusions, multiple roots, supernumerary roots and root dwarfism or gigantism are sometimes observed. ${ }^{4}$

Mandibular third molars anatomical disposition is practically unpredictable, ${ }^{5}$ and a correct diagnosis is therefore necessary for surgical management, prevention of complications and postoperative management. Radiographic study is essential, since identifying the point of least resistance is necessary in order to overcome the root anchoring in the alveolar bone with surgical maneuvers. ${ }^{6}$

Third molars have been radiographically classified according to their position with regard to the second molar and the mandibular branch. According to Pell \& Gregory, third molars can be categorized as level A, $\mathrm{B}$ or $\mathrm{C}$ according to their depth with regard to the occlusal plane, and as class I, II or III according to the available space (with regard to the ascending mandibular branch and the adjacent second molar). ${ }^{7}$ The position in space has been classified according to Winter in four inclination categories with regard to third molar longitudinal axis. ${ }^{8}$ Finally, Sánchez-Torres developed a classification based on third molar depth and direction, number, direction and shape of the
Table 1. Interpretation of the kappa values

\begin{tabular}{l|l}
\hline Kappa value & Strength of agreement \\
\hline$<0.000$ & Poor \\
$0.00-0.20$ & Slight \\
$0.21-0.40$ & Fair \\
$0.41-0.60$ & Moderate \\
$0.61-0.80$ & Substantial \\
$0.81-1.00$ & Perfect
\end{tabular}

roots and on complementary considerations such as the relationship with the inferior dental canal and the relationship with the second molar. This classification, which is less known than the previous ones and has not been previously assessed, ${ }^{9}$ considers a larger number of elements.

In the clinical, medical-legal and research fields, it is important for the same perception of a problem to be established for different observers. In the process of third molar categorization, Pell \& Gregory and Winter classifications are basic; the one by Sánchez Torres is a method that is used in Mexico. ${ }^{10}$ The purpose of this study was to assess the degree of agreement in the assessment of third molars according to these three classifications (Fig. 1), between a group of certified oral and maxillofacial surgeons and training residents.

\section{Method}

The study was conducted at the Oral Surgery Clinic of the Faculty of Stomatology of the Autonomous University of San Luis Potosí, in Mexico. Panoramic digital 
Table 2. Kappa values per group

\begin{tabular}{|c|c|c|c|}
\hline Group & Classification & Fleiss' Kappa & $p$ \\
\hline MFS & Sánchez-Torres & $0.125^{*}$ & $0.000^{* *}$ \\
\hline MFS & $\begin{array}{l}\text { Sánchez-Torres } \\
\text { (radicular component) }\end{array}$ & $0.105^{*}$ & $<0.001^{* *}$ \\
\hline MFC & Pell \& Gregory & $0.05^{*}$ & $0.0017^{\star *}$ \\
\hline MFC & Winter & $0.28^{*}$ & $0.000^{* *}$ \\
\hline Residents & Sánchez-Torres & $0.326^{*}$ & $0.000^{* *}$ \\
\hline Residents & $\begin{array}{l}\text { Sánchez-Torres } \\
\text { (radicular component) }\end{array}$ & $0.338^{*}$ & $<0.001^{\star *}$ \\
\hline Residents & Pell \& Gregory & $0.185^{\star}$ & $0.0017^{\star \star}$ \\
\hline Residents & Winter & $0.636^{*}$ & $0^{\star *}$ \\
\hline
\end{tabular}

radiographs of patients who attended the clinic were used; the study was submitted for approval by the Institutional Ethics Committee (CEI-FE-012018232072). The radiographs were only identified by age and gender of the patient they belonged to. The raters were 10 oral and maxillofacial surgeons and 10 residents of that specialty at the Ignacio Morones Prieto Central Hospital of San Luis Potosí, Mexico.

The 20 observers recorded the classification of the left and right mandibular molars according to Pell \& Gregory, Winter and Sánchez-Torres classifications. Each observer assessed 20 radiographs (10 left and 10 right third molars). Prior to the assessment, all of them were provided with a manual with the characteristics to be considered for each classification, in order for criteria to be standardized. The radiographs were randomly shown in digital images with sufficient sharpness and contrast. Data were recorded on collection sheets.

Statistical analysis was carried out with the R program, version 3.4, using the "irr" package. An agreement analysis was performed using Fleiss' kappa for multiple raters. The significance of the test was determined at $p<0.05$; interpretation of the kappa values (Table 1) was based on the table reported by Posner. ${ }^{11}$

\section{Results}

The results on the degrees of agreement can be observed in Table 2, which shows that the classification with the lowest degree of agreement was that of Pell \& Gregory, while Sánchez-Torres instrument had a slight degree of agreement for maxillofacial surgeons and a fair degree of agreement for residents. Sánchez-Torres classification had a similar degree of agreement in its coronal and spatial, as well as in the radicular anatomical components, which demonstrates that both maxillofacial surgeons and residents have a sound command of this instrument. Finally, the Winter classification showed the highest degree of agreement in both groups of observers.

\section{Discussion}

There is a reasonable justification for the need to group "objects" with similar characteristics in order to distinguish complex from simple entities. In medicine, diagnosis is an important classification process. ${ }^{12} \mathrm{~A}$ classification determines the response or reaction to an object or group of objects whose boundaries are clearly defined. ${ }^{12}$ There are multiple classifications for third molars, and the preference for using one or another lies with the surgeon's criteria and not with numerical parameters of its usefulness; there is no national or international standard, and most classifications have not been validated.

Routine dental procedures, such as fillings, endodontics or oral surgery, among others, are selected based on the severity, risks, anatomical characteristics and conditions of the patient. In these clinical scenarios, it is essential to correctly classify the pathological entity in order to reduce or prevent possible complications, as well as to select the most appropriate therapeutic approach for each patient. If the classification method lacks the capability to allow common agreement between observers, clinical procedures become difficult and hard to accomplish.

In addition to the usual clinical settings, a correct classification is vital for clinical research. Historically, Winter and Pell \& Gregory classifications have been used for different research designs around third molar surgery. Currently, they continue to be used to define selection criteria; ${ }^{13}$ however, other studies have focused on classifying patients only based on the degree of impaction of the third molar, ${ }^{14}$ which is related to the degree of bone resorption, especially in studies that have used the dental impaction pain model..$^{15}$

Lack of agreement can lead to legal controversies; for example, injury to the inferior alveolar nerve is one of the complications most commonly associated with discomfort and legal actions by the patient. ${ }^{16}$ For this reason, it is relevant for the degree of agreement on the interpretation of the classifications that are most commonly used by oral and maxillofacial surgeons to be determined.

Another aspect in the development of new scales and evaluation and classification instruments is that they 
require an adequate validation and reliability evaluation process. The validity of a diagnostic test is determined by the sensitivity, specificity and positive and negative predictive value of the test, which should ideally have values higher than or equal to $80 \%$ and that have the disadvantage of requiring a gold standard, which in third molar classifications does not exist. ${ }^{17}$ In turn, reliability refers to the degree at which similar results would be obtained after applying the measurement process more than once. ${ }^{18}$

With regard to dental retention, current classification systems are based on clinical and radiographic parameters ${ }^{16,19,20}$ to assess third molar position; however, they have been accepted without prior validation. ${ }^{21}$ Several studies have been found in the literature that estimate the degree of agreement of the Winter and Pell \& Gregory classifications; in the present work, it is interesting to observe the poor level agreement with the Pell \& Gregory classification (Table 2), which is accepted as standard in the classification of mandibular third molars. These results are consistent with those obtained by García et al. ${ }^{17}$ and Lima et al., ${ }^{22}$ who demonstrate that there is no reliability and validity in the classification criteria, since there are countless combinations between positions and classes, which makes categorization difficult.

Since 2000, García et al. ${ }^{17}$ reported that Pell \& Gregory classification is not useful for predicting the degree of surgical difficulty; in addition, it has been pointed out that it implies vast knowledge on the surgical technique ${ }^{23}$ and that its poor degree of agreement between observers is driven by its large number of categories; ${ }^{22}$ in addition, much of its variability is due to the subjective interpretation by the observer to determine which criterion to apply for each case. ${ }^{21}$

On the other hand, the results in the Winter classification show a substantially higher degree of agreement between training residents (kappa $=0.636$ ) than between maxillofacial surgeons (kappa $=0.28$ ), which are similar findings to those reported in 2012 by Lima et al., ${ }^{22}$ who indicated a degree of agreement higher than $78 \%$. It could be assumed that such degree of agreement is mainly due to the fact that only one anatomical characteristic of third molars is taken into account (direction of the piece), in comparison with the other variables used in the studied classifications, which is a fact that was confirmed by Almendros Marqués et al. ${ }^{21}$

To the best of our knowledge, the degree of agreement of the Sánchez-Torres classification has not been reported. This classification is thoroughgoing and at the same time complex, since it considers a large number of conditions. Nevertheless, unlike Pell \& Gregory's classification, it obtained a higher score (kappa $=0.12$ and 0.32 in maxillofacial surgeons and in residents Table 2). This result might be due to the fact that Sánchez-Torres' classification is more commonly used in Mexico, particularly in the training center where the study was carried out, although this does not clarify its relevance as a possible classification method.

This research had the following limitations: only one group of experts trained in the same surgical school was included; the kappa value showed a gradual and considerable decrease with the growing number of classification categories, ${ }^{24}$ which was reflected in low levels of agreement. In addition, in this type of study, observers may be concordantly wrong, even if it is at low levels.

The conduction of future research in order to validate these classifications is suggested and, to the extent possible, new methods should be defined, such as the one proposed by Juodzbalys and Daugela, ${ }^{25}$ based on parameters related to the surgical setting and that follow a validation process ${ }^{26}$ to confirm their usefulness, or based on data obtained from systematic reviews and meta-analyses, to ensure that they are efficient and relevant both in theory and in the clinical practice of one of the most common procedures in maxillofacial surgery.

\section{Conclusion}

Pell \& Gregory's classification had the lowest degree of agreement, followed by Sánchez-Torres' instrument; the Winter classification was shown to have higher capability for agreement between oral and maxillofacial surgeons, as well as between training residents.

\section{References}

1. Carter K, Worthington S. Predictors of third molar impaction: a systematic review and meta-analysis. J Dent Res. 2016;95:267-276.

2. Gay-Escoda C, Berini-Aytés L. Cordales incluidos: patología, clínica y tratamiento de tercer molar incluido. En: Gay-Escoda C, Berini-Aytés L. Tratado de cirugía bucal. Tomo I. España: Ediciones Ergón; 2004.

3. Marciani RD. Third molar removal: an overview of indications, imaging, evaluation, and assessment of risk. Oral Maxillofac Surg Clin North Am. 2007;19:1-13

4. Peñarrocha DM, Sanchis BJM, Sáez CU, Gay-Escoda C, Bagán SJV. Escala numérica de la valoración de la dificultad quirúrica en la extracción de 190 terceros molares mandibulares incluidos. Arch Odontoestomatol. 2000;16:96-100.

5. Phillips $\mathrm{C}$, White RP. How predictable is the position of third molars over time? J Oral Maxillofac Surg. 2012;70:11-14.

6. Fuster-Torres MA, Gargallo-Albiol J, Berini-Aytes L, Gay-Escoda C. Evaluation of the indication for surgical extraction of third molars according to the oral surgeon and the primary care dentist. Experience in the Master of Oral Surgery and Implantology at Barcelona University Dental School. Med Oral Patol Oral Cir Bucal. 2008;13:E499-E504. 
7. Pell GJ, Gregory GT. Impacted mandibular third molars: Classification and modified technique for removel. Dent Dig. 1933;330-338.

8. Winter G. Principles of exodontia as applied to the impacted third molar a complete treatise on the operative technic with clinical diagnoses and radiographic interpretations. EE. UU: American Medical Book Company; 1926.

9. Sánchez-Torres J, Reyes-Fuentes R. Clasificación de terceros molares inferiores retenidos. Valoración radiográfica. Rev Estomatol. 1969;63-70.

10. Olguín-Martinez TG, Amarillas-Escobar ED. Morfología radicular de los terceros molares. Rev ADM. 2017;1:17-24.

11. Posner KL, Sampson PD, Caplan RA, Ward RJ, Cheney FW. Measuring interrater reliability among multiple raters: An example of methods for nominal data. Stat Med. 1990;9:1103-1115.

12. Jutel A. Classification, disease, and diagnosis. Perspect Biol Med. 2011; 54:189-205.

13. Talimkhani I, Jamalpour MR, Babaei H, Faradmal J. Comparison of intra-socket bupivacaine administration versus oral mefenamic acid capsule for posoperative pain management following removal of impacted mandibular third molars. J Oral Maxillofac Surg. 2019:77:1365-1370.

14. Gay-Escoda C, Hanna M, Montero A, Dietrich T, Milleri S, Giergiel E, et al. Tramadol/dexketoprofen (TRAM/DKP) compared with tramadol/paracetamol in moderate to severe acute pain: results of a randomised, double-blind, placebo and active-controlled, parallel group trial in the impacted third molar extraction pain model (DAVID study). BMJ Open. 2019;9:e023715.

15. Cooper SA, Desjardins PJ. The value of the dental impaction pain model in drug development. En: Szallasi A (editor). Analgesia: methods and protocols, methods in molecular biology. EE. UU: Springer; 2010.

16. Maglione M, Costantinides F, Bazzocchi G. Classification of impacted mandibular third molars on cone-beam CT images. J Clin Exp Dent. 2015; 7:e224-e231.
17. García AG, Sampedro FG, Rey JG, Vila PG, Martin MS. Pell-Gregory classification is unreliable as a predictor of difficulty in extracting impacted lower third molars. Br J Oral Maxillofac Surg. 2000;38:585-587.

18. Van Stralen KJ, Stel VS, Reitsma JB, Dekker FW, Zoccali C, Jager KJ. Diagnostic methods I: sensitivity, specificity, and other measures of accuracy. Kidney Int. 2009;75:1257-1263.

19. Santosh P. Impacted mandibular third molars: review of literature and a proposal of a combined clinical and radiological classification. Ann Med Health Sci Res. 2015;5:229-234.

20. Ge J, Zheng JW, Yang C, Qian WT. Variations in the buccal-lingual alveolar bone thickness of impacted mandibular third molar: our classification and treatment perspectives. Sci Rep. 2016:6:1-9.

21. Almendros-Marqués N, Berini-Aytés L, Gay-Escoda C. Evaluation of intraexaminer and interexaminer agreement on classifying lower third molars according to the systems of Pell and Gregory and of Winter. J Oral Maxillofac Surg. 2008;66:893-899.

22. Lima CJ, Silva LC, Melo MR, Santos JA, Santos TS. Evaluation of the agreement by examiners according to classifications of third molars. Med Oral Patol Oral Cir Bucal. 2012:17:281-286.

23. Yuasa $\mathrm{H}$, Sugiura $\mathrm{M}$. Clinical postoperative findings after removal of impacted mandibular third molars: Prediction of postoperative facial swelling and pain based on preoperative variables. Br J Oral Maxillofac Surg. 2004;42:209-214.

24. Lantz CA, Nebenzahl E. Behavior and interpretation of the $\mathrm{K}$ statistic: Resolution of the two paradoxes. J Clin Epidemiol. 1996;49:431-434.

25. Juodzbalys G, Daugela P. Mandibular third molar impaction: Review of literature and a proposal of a classification. J Oral Maxillofac Res. 2013;4:1-11.

26. Stacchi C, Daugela P, Berton F, Lombardi T, Andriulionis T, Perinetti G, et al. A classification for assessing surgical difficulty in the extraction of mandibular impacted third molars: description and clinical validation. Quintessence Int. 2018;49:745-753. 